\title{
To Add Insight to Injury: Childhood Abuse, Abuse Perceptions, and the Emotional and Physical Health of Young Adults
}

\author{
RACHEL E. GOLDSMITH \\ Portland Veterans Affairs Medical Center, Portland, Oregon, USA \\ JENNIFER J. FREYD \\ University of Oregon, Eugene, Oregon, USA
}

ANNE P. DEPRINCE

University of Denver, Denver, Colorado, USA

\begin{abstract}
Although childhood abuse is strongly associated with psychological difficulties, survivors may not perceive their experiences as abusive. Depression, anxiety, dissociation, and physical health complaints may decrease perceptions of abuse and may also be exacerbated by individuals' abuse perceptions. The current study examined abuse perceptions, abuse experiences, and current symptoms among 185 university students. Ninety-six participants repeated the study 1-2 years later. At Time 1, self-labeling as "abused" or "maltreated" was not related to psychological or physical health symptoms. At Time 2, self-labeling as "abused" or "maltreated" was positively related to depression, anxiety, and dissociation. Results indicate that abuse
\end{abstract}

Received 5 June 2008; revised 7 October 2008; revised 21 November 2008; accepted 14 March 2009.

Support for this project was provided as part of the University of Oregon Psychology Department's National Institute of Mental Health training grant in development and psychopathology (NIMH \#5-T32-MH20012-04), the Beverly Fagot Dissertation Award from the Psychology Department of the University of Oregon, and a Graduate Research Support Grant from the University of Oregon. The project was also supported by the Fund for Research on Trauma and Oppression established by an anonymous donor. We thank Chris Baker, Carrie Bettenhausen, Angela Binder, Jonathan Cook, Christina Gamache, Mary Gray, Pete Happy, Linda Ivy, Mary Jacque, Rachel Phariss, Rebecca Silver, Jennifer Simonds, Tiegan Tidball, Carrie Wouda, and the University of Oregon Dynamics Lab for their help with this project.

Address correspondence to Rachel E. Goldsmith, Portland Veterans Affairs Medical Center (P3MHADM), 3710 SW Veterans Road, Portland, OR 97239. E-mail: Rachel.Goldsmith@va.gov 
perceptions may change over time and may be connected with emotional and physical symptoms.

KEYWORDS childhood abuse, maltreatment, labeling, awareness, perceptions, posttraumatic stress

Researchers and clinicians working with adult survivors of childhood abuse have identified several challenges related to individuals' perceptions of their own abuse experiences. For example, the literature increasingly points to serious obstacles in assessing abuse prevalence caused by underreporting of abuse (e.g., Smith et al., 2000; Wekerle et al., 2001). Longitudinal data indicate that young adults are inconsistent in reporting abuse, and that this unreliability stems from the provision of false-negative reports (Fergusson, Horwood, \& Woodward, 2000). Underreporting, whether caused by disruptions in awareness and memory of abuse (Freyd, DePrince, \& Gleaves, 2007; Herman, 1992; Linehan, 1993) or the "stigmatic and secretive nature" of abuse (e.g., Wekerle et al., 2001, p. 850), may present serious impediments to conducting psychotherapy with survivors of abuse, preventing the intergenerational perpetration of abuse, and obtaining accurate estimates of abuse prevalence.

In spite of the importance of the topic to both research and practice, few studies have examined how perceptions of abuse may relate to survivors' mental and physical health, or how such assessments change over time. Most research on abuse perceptions has relied on cross-sectional designs, and very few studies have considered the psychological or physical health correlates of abuse perceptions. The current study addresses these gaps by assessing the psychological and physical health correlates of abuse perceptions in a longitudinal sample of young adults.

\section{ABUSE PERCEPTIONS}

In a review of psychological studies of retrospective reports of abuse published between 1980 and 2001, approximately one-third of adults with substantiated cases of severe childhood abuse and neglect denied abuse occurrences (Hardt \& Rutter, 2004). Survivors of rape, sexual abuse, physical abuse, and emotional abuse often describe their victimization experiences behaviorally but do not categorize themselves as having been raped or abused (e.g., Goldsmith \& Freyd, 2005; Koss, 1998; Silvern, Waelde, Baughan, Karyl, \& Kaersvang, 2000).

Several studies have now documented considerable differences between survivors' perceptions of childhood abuse and researcher-defined abuse (e.g., Carlin et al., 1994; Knutson \& Selner, 1994; Rausch \& Knutson, 
1991; Silvern et al., 2000). For example, in a sample of 11,660 undergraduates, only $26 \%$ of students who met research criteria for exposure to severe physical punishment (including those who required medical attention for physical injuries deliberately inflicted by a parent) agreed with the item "I was physically abused ..." (Knutson \& Selner, 1994). College students who reported receiving punitive treatment similar to that of their siblings were more than twice as likely to identify their siblings' experiences as abusive as they were to label their own (Rausch \& Knutson, 1991). Participants were also likely to interpret parental treatment toward themselves (but not toward siblings) as deserved, and therefore not abusive.

\section{PSYCHOLOGICAL CORRELATES OF ABUSE PERCEPTIONS}

A handful of studies have examined psychological correlates of abuse perceptions. This research demonstrates that although many survivors of severe abuse experiences do not consider themselves to have been abused, abuse perceptions appear to be positively related to abuse severity (Carlin et al., 1994; Silvern et al., 2000; Wekerle et al., 2001). Associations between abuse perceptions and psychological symptoms appear more complex. Among 280 female clients in a family medical clinic, more women met researcher-defined criteria for abuse (28.2\%) than participant-defined criteria (11.4\%; Carlin et al., 1994). Women who met both criteria for abuse had the highest lifetime prevalence rate for depression (83\%), followed by those who met researcher-defined criteria for abuse (56\%), and finally by those who did not meet researcher or participant criteria for abuse (35\%).

Another study (Silvern et al., 2000) compared researcher-defined and participant-defined categorizations of physical and sexual abuse in 542 college students. Of those who self-defined as abused, 85.8\% met researcher definitions for abuse. Abuse, as defined by the researchers, was positively related to depression and other posttraumatic symptoms, and these relations were independent of self-defined abuse. In a study of 1,239 high school students and 224 adolescents served by Child Protective Services (CPS), Wekerle et al. (2001) reported that among those individuals who reported severe physical abuse or sexual abuse experiences, self-labelers of physical abuse or sexual abuse did not differ from non-self-labelers on psychological symptoms. However, for emotional abuse, self-labeling as abused was associated with more psychological difficulties.

Taken together, these studies indicate that abuse severity may be positively related to both abuse perceptions and to psychological symptoms. The study by Silvern et al. (2000) indicated that participants' abuse perceptions did not affect the relation between psychological symptoms and researcher-defined abuse. This finding mirrors Harned's (2004) examination of three path analysis models to explain the relation between labeling 
unwanted sexual experiences and negative psychological consequences in a cross-sectional sample of 1,395 women. The experiences themselves, rather than the victims' appraisals of the events as sexual abuse or assault, were related to psychological difficulties. These studies provide valuable information regarding associations between abuse severity, abuse perceptions, and mental health. However, longitudinal research may help clarify the factors that relate to abuse perceptions and how these processes relate to psychological health over time.

\section{WHY WOULDN'T PEOPLE LABEL ABUSE AS ABUSE?}

Many researchers have suggested that the shameful and secretive nature of abuse decreases the likelihood that people will label themselves as having been abused (e.g., Wekerle et al., 2001). In many abusive environments, perceptions of victimization may be maladaptive or unsafe (Freyd, 1996; Freyd et al., 2007). Thus, labeling caregiver abuse as abuse may come with psychological costs (e.g., Briere, 1992; Freyd, 1996; Freyd et al., 2007). Children exposed to abuse by caregivers may develop strategies to isolate knowledge of the abuse and abuse-related emotions. Associations between childhood abuse and dissociation (Chu \& Dill, 1990; Ogawa, Sroufe, Weinfield, Carlson, \& Egeland, 1997; Putnam et al., 1996), and between dissociation and information processing (e.g., Becker-Blease, Freyd, \& Pears, 2004; Freyd \& DePrince, 2001), have prompted interest in the role that dissociation may play in preventing perceptions of abuse.

Aspects of abuse experiences themselves may also increase the likelihood that disruptions in perceptions about the abuse will occur. Some abusive environments teach children that they are wrong in their own assessments of their emotional experiences (Linehan, 1993). Childhood emotional abuse and neglect are associated with alexithymia (difficulty identifying and describing feelings) in clinical and nonclinical samples (Goldsmith \& Freyd, 2005; Zlotnick, Mattia, \& Zimmerman, 2001). In addition, strong associations between abuse, depression, and anxiety (e.g., Springer, Sheridan, Kuo, \& Carnes, 2007) raise the possibility that children may internalize abuserelated distress by blaming themselves and becoming depressed (Briere, 1992). Abuse sequelae such as alexithymia, dissociation, and depression may prevent survivors from developing perceptions that they were abused.

Perceptions of childhood experiences may relate to a range of emotional reactions. When individuals disclose abuse, people may disbelieve victims or convey blame or shame, which can be devastating reactions. The quality of listeners' responses to abuse disclosure is related to victims' subsequent psychological functioning (Ullman, 2003). Brown and Freyd (2008) proposed that conscious reappraisals of abuse may provoke a psychological crisis. Symptoms of depression or anxiety may also lead survivors to seek 
psychological treatment, which could affect perceptions of childhood experiences. It is also possible that perceptions of abuse could ameliorate psychological symptoms by shifting patterns of internalization among abused individuals.

\section{CURRENT STUDY}

The current study tests several theoretically driven predictions and extends the current literature on abuse perceptions by considering associations among abuse perceptions, psychological symptoms, and reported physical health over time. First, we set out to examine abuse perceptions using a longitudinal method in a sample of college students. We hypothesized that participants would respond differently to abuse-labeling questions according to the specific words used in the question (see Bonomi, Allen, \& Holt, 2006). We aimed to compare participants' responses to questions that asked whether they were "abused" to the same questions that used the word "maltreated."

Based on prior data regarding the stability of abuse reports in young adults (Fergusson et al., 2000), we predicted that some participants would change their abuse perceptions. We expected that psychological symptoms would be interrelated and strongly associated with both abuse perceptions and the extent of childhood abuse experiences participants reported. In addition, we hypothesized that abuse perceptions would be positively related to psychological symptoms after controlling for abuse severity. Analyses were planned to investigate these associations both cross-sectionally (by evaluating associations among symptoms and abuse perceptions at both Time 1 and Time 2) and longitudinally (by investigating whether abuse labeling at Time 1 would predict symptoms at Time 2 , and if symptoms at Time 1 would predict abuse perceptions at Time 2 or changes in abuse perceptions from Time 1 to Time 2). We also collected participants' qualitative descriptions of whether their perceptions of abuse experiences changed over time, and if so, the reasons for changes in their perceptions.

\section{METHOD}

\section{Participants}

Participants were 185 university students enrolled in introductory psychology or linguistics courses who indicated that they intended to remain based in the same geographical area for the next 1-2 years, and that they would be willing to be contacted in 1-2 years for a paid, follow-up questionnaire session. Surveys included instructions for creating an anonymous code for the purposes of matching up Time 1 and Time 2 data. However, five participants 
TABLE 1 Participant Demographic Characteristics for Time 1 and Time 2

\begin{tabular}{lcc}
\hline & Time 1 & Time 2 \\
\hline Total Participants & 185 & 96 \\
Gender & & \\
$\quad$ Females & $126(68.1 \%)$ & $71(74 \%)$ \\
Males & $59(31.9 \%)$ & $25(26 \%)$ \\
Ethnicity & & \\
Asian & 0 & $2(2.1 \%)$ \\
Asian American & $11(5.9 \%)$ & $6(6.3 \%)$ \\
Black/African American & $4(2.2 \%)$ & $2(2.1 \%)$ \\
Hispanic/Latina/Latino & $5(2.7 \%)$ & $4(4.2 \%)$ \\
Native American/American Indian & $4(2.2 \%)$ & $3(3.1 \%)$ \\
White/European American & $153(82.7 \%)$ & $75(78.1 \%)$ \\
Other & $5(2.7 \%)$ & $4(4.2 \%)$ \\
Multiethnic & $2(1.2 \%)$ & 0 \\
Unspecified & $1(0.5 \%)$ & 0 \\
\hline
\end{tabular}

created codes at Time 2 that could not be matched to Time 1 codes. At Time 1, participants included 126 women and 59 men whose ages ranged from 18 to 32 years, with $88.6 \%$ of participants between the ages of 18 and $21(M=19.21, S D=1.74)$. Time 2 participants were 96 individuals $(51.9 \%)$ from the original sample. Table 1 provides demographic information for this sample. There were no significant differences in the demographic characteristics or trauma-related variables of interest between Time 1 and Time 2 participants.

\section{Procedure}

Participants signed up to complete an anonymous questionnaire about life experiences. Participants were told both verbally and via the informed consent that some of the questions were personal and potentially upsetting; the words abuse and trauma were not used. Participants were informed that there was an optional follow-up component to the study that would take place within the following 1-2 years. After 1 year, participants were contacted and invited to participate in the Time 2 questionnaire. At both time points, participants completed informed consent forms and self-report questionnaires. No individuals declined to participate. After completing the questionnaires, participants then received debriefing forms that explained the rationale for the measures used in the questionnaires. Participants were not expected to remember their responses from Time 1 to Time 2. At Time 1, participants received course credit for their participation. At Time 2, participants were given their choice of $\$ 10.00$ or course credit. Research procedures were approved by the university's institutional review board. 


\section{Materials}

Questionnaires included demographic questions regarding individuals' gender and ethnicity, and six questions regarding perceptions of physical, sexual, and emotional abuse that preceded measures of psychological symptoms and abuse experiences. Three of these questions used the word abused (e.g., "Would you say that you were emotionally or psychologically abused as a child [before age 17]?"), and three questions used the word maltreated (e.g., "Would you say that you were sexually maltreated as a child [before age 17]?"). Therefore there were two questions for each abuse subtype, one using the word abused and the other using the word maltreated. Surveys at Time 1 and Time 2 were identical, except that the Time 2 questionnaire concluded with open-ended questions that asked participants if they had changed their perceptions of whether or not they had been abused or maltreated, and if so, why their thoughts about this had changed.

The Toronto Alexithymia Scale (TAS-20; $\alpha=.74-.84$; Parker, Bagby, Taylor, Endler, \& Schmitz, 1993) is the most frequently used measure of alexithymia (Taylor, 2000). Participants respond to statements using Likert scales that range from 1 to 5, with higher scores representing a greater degree of alexithymia, except for reverse-scored items. Examples of statements include, "I am often confused about what emotion I am feeling," and "I don't know what's going on inside me." In the current sample, $\alpha=.84$ at Time 1 and .86 at Time 2 , and test-retest reliability was good $(r=.65$, $p<.001)$.

The Trauma Symptom Checklist-40 (TSC-40; $\alpha=.90$, subscales .62-.77; Elliott \& Briere, 1992) queries a range of posttraumatic symptoms using a Likert scale that ranges from 0 (never) to 3 (often). Previous research has demonstrated the construct validity of the TSC-40 and its convergent validity when compared with the Symptom Checklist-90 (SCL-90), a widely used psychological symptom inventory (Zlotnick et al., 1996). The scale has six subscales: (a) dissociation, (b) anxiety, (c) sexual abuse trauma, (d) sleep disturbance, (e) sexual problems, and (f) depression. Subscale scores are computed by totaling the items that contribute to each subscale. This study used the depression, anxiety, and dissociation subscales in its analyses because those symptoms are commonly related to different forms of interpersonal trauma. Alpha reliabilities were .92 at Time 1 and .94 at Time 2, and test-retest reliability for total TSC-40 scores was high $(r=.80, p<.001)$.

The Pennebaker Inventory of Limbic Languidness-time bound (PILL- $t$; Pennebaker, 1982) is a 54-item scale that taps the frequency of occurrence of a group of common physical symptoms and sensations over the past month, with response options from almost never to almost daily. The PILL has high internal consistency $(\alpha=.91)$ and adequate 2 -month test-retest reliability ( $r=.83$; Pennebaker, 1982). In the current sample, $\alpha=.92$ at Time 1 and .94 at Time 2 , and test-retest reliability was good $(r=.69, p<.001)$. 
The Child Abuse and Trauma Scale (CAT scale; Sanders \& BeckerLausen, 1995) was designed to measure "the individual's present, subjective perception of the degree of stress or trauma present in his/her childhood" [emphasis in the original] (p. 317). Examples of scale items include, "Did you feel safe living at home?" and "As a child, did you feel unwanted or emotionally neglected?" The measure uses a Likert scale of $0-4$, where 0 denotes never; 1 , rarely; 2, sometimes; 3 , very often; and 4, always. Total scores on the measure are divided by the number of items to produce a mean score. A higher score signifies greater levels of maltreatment; some items, such as the first example above, are reverse coded. The CAT scale has strong test-retest reliability $(r=.71-.91)$ and internal consistency ( $\alpha=.63-.90$; Kent \& Waller, 1998). For the current sample, $\alpha=.92$ at Time 1 and .93 at Time 2, and test-retest reliability in the current sample was high $(r=.85, p<.001)$.

\section{RESULTS}

Participants who responded that they had experienced any form of abuse or maltreatment were considered as having labeled themselves as "abused." We coded this response as $0=$ labeled nonabused and $1=$ labeled abused . Five participants did not include abuse or maltreatment labels at Time 1, and one participant did not include abuse or maltreatment labels at Time 2 . In addition, we assessed whether individuals had changed their perceptions over time, which we coded as $0=$ no change in abuse perceptions and $1=$ changed abuse perceptions between Time 1 and 2. Table 2 provides the number of participants who endorsed each abuse or maltreatment label at Time 1 and 2 and the reliability for reporting each abuse or maltreatment subtype.

Responses on the six abuse perception questions were each intercorrelated at levels below $p<.05$ at both time points, with the exception of the correlations between sexual abuse and emotional maltreatment $(r=.13, p=$ .09) and between physical abuse and sexual maltreatment $(r=.04, p=.55)$

TABLE 2 Numbers of Participants Endorsing Abuse or Maltreatment Labels at Time 1 and 2

\begin{tabular}{lccc}
\hline Abuse perception & Time 1 & Time 2 & Reliability $(r)$ \\
\hline Sexually abused & 8 & 8 & $.69^{*}$ \\
Physically abused & 10 & 5 & $.65^{*}$ \\
Emotionally abused & 29 & 21 & $.64^{*}$ \\
Sexually maltreated & 11 & 11 & $.65^{*}$ \\
Physically maltreated & 9 & 8 & $.50^{*}$ \\
Emotionally maltreated & 30 & 21 & $.64^{*}$ \\
Any label of abuse or maltreatment & 43 & 29 & $.61^{*}$ \\
\hline
\end{tabular}

${ }^{*} p<.001$. 
at Time 1, and the correlations between sexual abuse and physical maltreatment $(r=.18, p=.08)$ and sexual maltreatment and emotional maltreatment $(r=.12, p=.23)$ at Time 2 . Of the 43 individuals who labeled themselves as having been either abused or maltreated at Time 1, 25 participated in the Time 2 portion of the study. There was no significant change in the rates of abuse labeling from Time 1 to Time 2. Twelve individuals reported that they had changed their perceptions regarding whether they were abused or maltreated, but in fact, 15 individuals changed whether or not they labeled themselves as abused or maltreated from Time 1 to Time 2. Table 3 indicates changes in abuse perception responses from Time 1 to Time 2.

Table 4 reports descriptive statistics for participants' levels of childhood abuse, alexithymia, depression, anxiety, dissociation, and physical health complaints. Every bivariate correlation between these variables was significant at the level of $p<.01$ at both time points.

At both Time 1 and 2, abuse labeling was correlated at $r=.60, p<.001$ with the extent of childhood abuse as measured by the total CAT scale score. At both Time 1 and 2, perceptions of sexual abuse and sexual maltreatment were correlated with CAT scale total scores at levels of $p<.05$, whereas perceptions of physical and emotional abuse and maltreatment were correlated with CAT scale total scores at levels of $p<.001$. Participants' scores on the CAT scale at Time 1 and Time 2 were highly correlated $(r=.85, p<.001)$. Means and standard deviations on the CAT scale were similar to those reported by Sanders and Becker-Lausen (1995) in undergraduate samples.

Hierarchical regression analyses demonstrated that at Time 1, the CAT scale total score was a significant predictor of participants' depression $\left(R^{2}(1,163)=.10, p<.001\right)$, but labeling abuse did not add significantly to

TABLE 3 Changes in Abuse Perceptions from Time 1 to 2

\begin{tabular}{lcc}
\hline & $\begin{array}{c}\text { Labeled abused } \\
\text { Time 1 }\end{array}$ & $\begin{array}{c}\text { Did not label abused } \\
\text { Time 1 }\end{array}$ \\
\hline Labeled Abused Time 2 & 19 & 10 \\
Did Not Label Abused Time 2 & 5 & 56 \\
\hline
\end{tabular}

TABLE 4 Descriptive Statistics for Study Measures

\begin{tabular}{lcc}
\hline Measure or subscale & Time 1 & Time 2 \\
Mean $(S D)$ & Mean $(S D)$ \\
\hline TAS-20 total & $45.60(10.79)$ & $45.32(11.40)$ \\
TSC-40 total & $24.28(14.04)$ & $25.39(16.15)$ \\
Depression & $6.40(3.51)$ & $6.92(4.48)$ \\
$\quad$ Anxiety & $4.88(3.77)$ & $5.23(3.81)$ \\
Dissociation & $2.57(1.93)$ & $2.41(2.00)$ \\
CAT scale total & $.68(.43)$ & $.76(.51)$ \\
PILL total & $66.64(23.43)$ & $66.72(228.43)$ \\
\hline
\end{tabular}


the model. At Time 2, CAT scale totals significantly predicted depression. Adding abuse labeling significantly improved the model. Therefore CAT scale total scores and labeling abuse both emerged as significant independent predictors for depression. Results revealed a similar pattern for anxiety and CAT scores. At Time 1, the CAT scale total score significantly predicted anxiety $\left(R^{2}(1,159)=.11, p<.001\right)$, but labeling abuse did not add significantly to the model. CAT scale total scores significantly predicted anxiety at Time 2. Abuse labeling significantly improved the model. The same pattern emerged for dissociation. At Time 1, CAT scale total scores predicted dissociation $\left(R^{2}(1,162)=.07, p=.001\right)$, but labeling abuse did not add significantly to model. However, at Time 2, CAT scale total scores significantly predicted dissociation, and adding abuse labeling significantly improved the model. Table 5 illustrates the relations of CAT scale total scores and abuse labeling to TSC-40 depression, anxiety, and dissociation scores at Time 2.

Hierarchical regression analyses using physical health as the dependent variable were somewhat more complex. At Time 1, the CAT scale total score was a significant predictor of participants' total physical health complaints $\left(R^{2}(1,164)=.09, p<.001\right)$, but abuse labeling did not add significantly to the model. At Time 2, CAT scale total scores again significantly predicted physical health complaints $\left(R^{2}(1,82)=.11, p=.002\right)$. Adding abuse labeling produced a significant change in the model $\left(R^{2}\right.$ change $\left.(1,81)=.05, p=.04\right)$. However, in the new model with both CAT scale total scores and abuse labeling as predictors, abuse labeling was a significant predictor $(\beta=.27$, $p=.04)$, whereas the relation between CAT scale total scores and physical health complaints was no longer significant $(\beta=.17, p=.18)$.

In order to ascertain whether labeling responses at Time 1 could predict depression, anxiety, physical health symptoms, alexithymia, or dissociation at Time 2, hierarchical regressions were conducted that controlled for CAT scale total scores. Self-labeling as abused at Time 1 did not predict any psychological or physical symptoms at Time 2. Logistic regressions were conducted to evaluate whether symptoms at Time 1 could predict abuse labeling at Time 2. No psychological symptoms at Time 1 predicted abuse labeling at Time 2 or changes in abuse perceptions, with the exception that anxiety at Time 1 predicted labeling abuse at Time 2, even after controlling for abuse severity. Anxiety scores at Time 1 produced an odds ratio of 1.25 (95\% confidence interval [CI] 1.03-1.52) times the likelihood of labeling abuse at Time 2 per unit of measurement on the anxiety subscale of the TSC-40, controlling for CAT scale total scores.

\section{Samples of Participant Responses Regarding Reasons} for Changes in Self-Labeling

Fifteen study participants provided brief descriptions of their understanding of the processes through which they changed their perceptions of their 
TABLE 5 Summary of Hierarchical Regression Analyses for Variables Predicting TSC-40 Subscale Scores at Time $2(N=96)$

\begin{tabular}{|c|c|c|c|}
\hline \multicolumn{4}{|c|}{ Dependent Variable: Depression } \\
\hline Variable & $B$ & $S E B$ & $\beta$ \\
\hline $\begin{array}{l}\text { Step } 1 \\
\text { CAT scale total score }\end{array}$ & .12 & .02 & $.52^{* * *}$ \\
\hline $\begin{array}{l}\text { Step } 2 \\
\text { CAT scale total score } \\
\text { Abuse labeling }\end{array}$ & $\begin{array}{r}.08 \\
2.75\end{array}$ & $\begin{array}{r}.03 \\
1.10\end{array}$ & $.35^{*}$ \\
\hline \multicolumn{4}{|c|}{$\begin{array}{l}\text { Note. } R^{2}=.26 \text { for Step } 1 ; \Delta R^{2}=.05 \text { for Step } 2(p<.05) .{ }^{\dagger} p<.05 ;{ }^{*} p<.01 ; \\
*\end{array}$} \\
\hline \multicolumn{4}{|c|}{ Dependent Variable: Anxiety } \\
\hline Variable & $B$ & $S E B$ & $\beta$ \\
\hline $\begin{array}{l}\text { Step } 1 \\
\text { CAT scale total score }\end{array}$ & .11 & .02 & $.53^{* *}$ \\
\hline $\begin{array}{l}\text { Step } 2 \\
\text { CAT scale total score } \\
\text { Abuse labeling }\end{array}$ & $\begin{array}{r}.07 \\
2.75\end{array}$ & $\begin{array}{l}.02 \\
.90\end{array}$ & $\begin{array}{l}.34^{*} \\
.33^{*}\end{array}$ \\
\hline \multicolumn{4}{|c|}{ Note. $R^{2}=.28$ for Step $1 ; \Delta R^{2}=.07$ for Step $2(p<.01) .{ }^{*} p<.01 ; * * p<.001$. } \\
\hline \multicolumn{4}{|c|}{ Dependent Variable: Dissociation } \\
\hline Variable & $B$ & $S E B$ & $\beta$ \\
\hline $\begin{array}{l}\text { Step } 1 \\
\quad \text { CAT scale total score }\end{array}$ & .05 & .01 & $.49^{* * *}$ \\
\hline $\begin{array}{l}\text { Step } 2 \\
\text { CAT scale total score } \\
\text { Abuse labeling }\end{array}$ & $\begin{array}{c}.04 \\
1.0\end{array}$ & $\begin{array}{l}.01 \\
.47\end{array}$ & $\begin{array}{l}.35^{* * *} .24^{*} \\
.\end{array}$ \\
\hline
\end{tabular}

abuse experiences, even though only 12 stated that they had changed their perceptions. Eight responses highlighted cognitive processes and included phrases such as "rethinking, reevaluating," "thinking about things again," "thinking more," "realizing," and "I understand more clearly now." Three participants identified counseling or classes as factors that influenced changes in their perceptions, and three noted that life changes including "separation from the perpetrator" and "having my own child" had impacted the change in their perceptions. One person replied, "I don't remember."

For example, a 20-year-old European American female self-labeled as emotionally abused at both time points, although she claimed to have changed her abuse perception. She described the changes as having resulted from "two more years of living, being apart from the person who maltreated me, changes in and a better relationship with the person who maltreated me." Another participant, a 21-year-old Asian American female, 
did not self-label as abused or maltreated at either time point, but wrote that, "My reasoning changed after taking psychology classes." A 21-year-old European American female did not self-label as abused or maltreated at Time 1, but at Time 2 self-labeled as emotionally maltreated. She wrote, "I realized my parents are both alcoholics and a lot of their behavior towards me was stressful and inappropriate." Other individuals may have been unaware of the reasons for changes in their perceptions or unwilling to report them. For example, a 20-year-old European American female who did not self-label as abused or maltreated at Time 1, but self-labeled as sexually maltreated at Time 2 , wrote that "something triggered me to see it more clearly."

\section{DISCUSSION}

The results demonstrate that young adults' appraisals of their experiences as "abuse" or "maltreatment" are related to abuse severity and are likely to change over time for a minority of individuals. Some participants' abuse perceptions differed according to whether the question included the word abused or maltreated. Self-labeling as abused or maltreated was not related to psychological symptoms at Time 1 , but was related to symptoms of anxiety, depression, and dissociation at Time 2 . The results replicate the connection between abuse severity and abuse labeling identified by Silvern et al. (2000), and it demonstrates that abuse labeling is related to psychological functioning, even after controlling for the amount of abuse that individuals experienced.

These findings are congruent with the results from Wekerle et al. (2001) that indicate associations between emotional difficulties and selflabeling as emotionally abused, but contrast with that study's finding that labeling sexual or physical abuse experiences was not associated with psychological symptoms. Depression, dissociation, and anxiety were intercorrelated, a result that highlights the possibility that for survivors of trauma, such symptoms may represent a generalized response rather than a reflection of separate disorders (Deering, Glover, Ready, Eddleman, \& Alarcon, 1996; Ross, 2000). Participants' descriptions of their changes in abuse perceptions suggest that many thoughts and experiences, both explicit and implicit, may relate to abuse perceptions.

Limitations of the present study include the sample's limited age range and ethnocultural homogeneity. It is certainly possible that perceptions of abuse experiences may be less distressing for older adults. A larger sample size would have allowed for additional analyses, including the effects of labeling each abuse subtype and of changing perceptions over time. In addition, many participants in the original sample did not return for the Time 2 portion of the study. 
The language researchers and clinicians choose in questioning participants about abuse experiences influences individuals' responses (see Bonomi et al., 2006), especially given that the mechanisms we investigated involved the ways abuse survivors use language to express or internalize their emotions and experiences. The importance of the wording of abuselabeling questions is evident from the differing numbers of individuals who identified as "abused" versus those who identified as "maltreated." Abuselabeling questions could have been expanded to assess additional aspects of abuse perceptions, and they could have included questions about neglect, a common form of child maltreatment with severe negative consequences (e.g., Erickson \& Egeland, 2002).

Studying childhood abuse using retrospective self-report data has both advantages and disadvantages. Kendall-Tackett and Becker-Blease (2004) noted that prospective studies may miss a considerable number of cases of abuse; that identified abuse may lead to interventions that interrupt some psychological consequences of maltreatment; and that unreported abuse may be more severe. Brewin, Andrews, and Gotlib (1993) demonstrated that available data, including those from prospective studies (e.g., Horwitz, Widom, McLaughlin, \& White, 2001), do not support mood-congruent hypotheses of reporting abuse experiences (Brewin et al., 1993). Negative affect is more likely a consequence of abuse than a cause of negative memories (Melchert, 1998). However, it is possible that identifying oneself as abused relates to symptom reports (KendallTackett \& Becker-Blease, 2004). Other important considerations include the potential influences of demand characteristics, as well as the societal and cultural understandings of relations between abuse and symptoms that individuals incorporate into reflections of their experiences.

Why might self-labeling as "abused" affect psychological symptoms beyond the effects of abuse severity at Time 2 but not at Time 1? These results echo variations in findings from previous studies (Carlin et al., 1994; Silvern et al., 2000; Wekerle et al., 2001) that have identified a relation between abuse labeling and increased psychological difficulties with some samples and circumstances but not in others. There are several possible reasons for the differences observed in the psychological correlates of abuse labeling at Time 1 and Time 2. At Time 1, many individuals were in their first year of college. For those that experienced abuse, this may have been their first time away from an abusive childhood environment. First-year college students have had little time away from home in which to reflect on their childhood experiences and to develop additional perspectives. In addition, transitions to college may have demanded emotional and cognitive resources that precluded reappraisals of childhood experiences. Finally, the initial questionnaire experience may have served as an intervention. It is possible that individuals had not previously been asked whether they had been abused or about specific childhood abuse experiences, and responding yes to such a question could have been their first instance of acknowledging 
abuse. Although no individuals indicated that the initial questionnaire affected their abuse perceptions or memories, the Time 1 questionnaire may have instigated reappraisals of past experiences without instilling explicit awareness for such changes.

The strong relation between self-labeling of abuse experiences and abuse severity suggests that environments with more abuse have a greater likelihood of leading to individuals' perceptions of abuse. However, the remaining disparity between self-labeling of abuse and reported abuse experiences may reflect unawareness for abuse comprised of both individual accommodations to abusive environments and a more general societal unawareness or even denial regarding abuse and its effects. Perceptions of abuse among survivors may be influenced by variations in levels of awareness and training regarding childhood abuse among psychologists (Courtois, 2002; van der Kolk, Weisaeth, \& van der Hart, 1996) and in the broader culture (e.g., Herman, 1992). Many mental health providers focus on anxiety, depression, or other symptoms without investigating the possibility of childhood abuse (e.g., Ross, 2000). Individuals' abuse perceptions and identities may be influenced by contact with psychological models, research, and interventions. Different perceptions of abuse may determine the resources survivors seek and health professionals' approach to patients' symptoms during treatment.

The present study suggests that among young adults, perceptions of having been abused or maltreated may predict psychological distress beyond the abuse itself. Survivors' psychological symptoms may reflect different processes that operate in discrete stages following trauma (Shalev, 1996). Future studies, including those with broader samples and over longer time periods, may provide helpful information for psychologists. Current understandings of abuse perceptions would be advanced by additional research regarding the mental health correlates of changes in abuse perceptions and by studies that investigate different abuse subtypes in greater detail. Such research could also incorporate the development of measures of abuse perceptions. Additional understanding of the emotional and appraisal processes that occur among abuse survivors may inform mental health professionals to provide appropriate support and care for this population.

\section{REFERENCES}

Becker-Blease, K. A., Freyd, J. J., \& Pears, K. C. (2004). Preschoolers' memory for threatening information depends on trauma history and attentional context: Implications for the development of dissociation. Journal of Trauma E Dissociation, 5(1), 113-131.

Bonomi, A. E., Allen, D. G., \& Holt, V. L. (2006). Conversational silence, coercion, equality: The role of language in influencing who gets identified as abused. Social Science \& Medicine, 62(9), 2258-2266. 
Brewin, C. R., Andrews, B., \& Gotlib, I. H. (1993). Psychopathology and early experience: A reappraisal of retrospective reports. Psychological Bulletin, 113, 82-98.

Briere, J. (1992). Child abuse trauma: Theory and treatment of the lasting effects. Newbury Park, CA: Sage.

Brown, L. S., \& Freyd, J. J. (2008). PTSD criterion A and betrayal trauma: A modest proposal for a new look at what constitutes danger to self. Trauma Psychology Newsletter, 3(1), 11-15.

Carlin, A. S., Kemper, K., Ward, N. G., Sowell, H., Gustafson, B., \& Stevens, N. (1994). The effect of differences in objective and subjective definitions of childhood physical abuse on estimates of its incidence and relationship to psychopathology. Child Abuse \& Neglect, 18(5), 393-399.

Chu, J. A., \& Dill, D. L. (1990). Dissociative symptoms in relation to childhood physical and sexual abuse. American Journal of Psychiatry, 147, 887-892.

Courtois, C. A. (2002). Traumatic stress studies: The need for curricula inclusion. Journal of Trauma Practice, 1, 33-58.

Deering, C. G., Glover, S. G., Ready, D., Eddleman, H. C., \& Alarcon, R. D. (1996). Unique patterns of comorbidity in posttraumatic stress disorder from different sources of trauma. Comprehensive Psychiatry, 37(5), 336-346.

Elliott, D., \& Briere, J. (1992). Sexual abuse trauma among professional women: Validating the trauma symptom checklist-40 (TSC-40). Child Abuse \& Neglect, 16, 391-398.

Erickson, M. F., \& Egeland, B. (2002). Child neglect. In J. Briere, L. Berliner, C. T. Hendrix, C. Jenny, \& T. Reid (Eds.), The APSAC handbook on child maltreatment (2nd ed., pp. 3-20). Thousand Oaks, CA: Sage.

Fergusson, D. M., Horwood, L. J., \& Woodward, L. J. (2000). The stability of child abuse reports: A longitudinal study of the reporting behavior of young adults. Psychological Medicine, 30, 529-544.

Freyd, J. J. (1996). Betrayal trauma: The logic of forgetting childhood abuse. Cambridge, MA: Harvard University Press.

Freyd, J. J., \& DePrince, A. P. (2001). Perspectives on memory for trauma and cognitive processes associated with dissociative tendencies. Journal of Aggression, Maltreatment \& Trauma, 4(2), 137-163.

Freyd, J. J., DePrince, A., \& Gleaves, D. H. (2007). The state of betrayal trauma theory: Reply to McNally (2007), Conceptual issues, and future directions. Memory, 15, 295-311.

Goldsmith, R. E., \& Freyd, J. J. (2005). Awareness for emotional abuse. Journal of Emotional Abuse, 5(1), 95-123.

Hardt, J., \& Rutter, M. (2004). Validity of adult retrospective reports of adverse childhood experiences: Review of the evidence. Journal of Child Psychology and Psychiatry, 45(2), 260-273.

Harned, M. S. (2004). Does it matter what you call it? The relationship between labeling unwanted sexual experiences and distress. Journal of Consulting $\mathcal{E}$ Clinical Psychology, 72(6), 1090-1099.

Herman, J. L. (1992). Trauma and recovery. New York: Basic Books.

Horwitz, A. V., Widom, C. S., McLaughlin, J., \& White, H. R. (2001). The impact of childhood abuse and neglect on adult mental health: A prospective study. Journal of Health and Social Behavior, 42, 184-201. 
Kendall-Tackett, K., \& Becker-Blease, K. (2004). The importance of retrospective findings in child maltreatment research. Child Abuse \& Neglect, 28, 723-727.

Kent, A., \& Waller, G. (1998). The impact of childhood emotional abuse: An extension of the child abuse and trauma scale. Child Abuse \& Neglect, 22(5), 393-399.

Knutson, J. F., \& Selner, M. B. (1994). Punitive childhood experiences reported by adults over a 10-year period. Child Abuse \& Neglect, 18(2), 155-166.

Koss, M. P. (1998). Hidden rape: Sexual aggression and victimization in a national sample of students in higher education. In M. E. Odem \& J. Clay-Warner (Eds.), Confronting rape and sexual assault (pp. 51-69). Wilmington, DE: Scholarly Resources.

Linehan, M. M. (1993). Cognitive-behavioral treatment of borderline personality disorder. New York: Guilford Press.

Melchert, T. P. (1998). Family of origin history, psychological distress, quality of childhood memory, and content of first and recovered childhood memories. Child Abuse \& Neglect, 22(12), 1203-1216.

Ogawa, J. R., Sroufe, L. A., Weinfield, N. S., Carlson, E. A., \& Egeland, B. (1997). Development of the fragmented self: Longitudinal study of dissociative symptomatology in a nonclinical sample. Development and Psychopathology, 9(4), 855-879.

Parker, J. D. A., Bagby, R. M., Taylor, G. J., Endler, N. S., \& Schmitz, P. (1993). Factorial validity of the 20-item Toronto alexithymia scale. European Journal of Personality, 7, 221-232.

Pennebaker, J. W. (1982). The psychology of physical symptoms. New York: Springer-Verlag.

Putnam, F. W., Carlson, E. B., Ross, C. A., Anderson, G., Clark, P., Torem, M., et al. (1996). Patterns of dissociation in clinical and nonclinical samples. Journal of Nervous and Mental Disease, 184(11), 673-679.

Rausch, K., \& Knutson, J. F. (1991). The self-report of personal punitive childhood experiences and those of siblings. Child Abuse \& Neglect, 15, 29-36.

Ross, C. A. (2000). The trauma model: A solution to the problem of comorbidity in psychiatry. Richardson, TX: Manitou Communications.

Sanders, B., \& Becker-Lausen, E. (1995). The measurement of psychological maltreatment: Early data on the child abuse and trauma scale. Child Abuse $\mathcal{E}$ Neglect, 19(3), 315-323.

Shalev, A. Y. (1996). Stress versus traumatic stress: From acute homeostatic reactions to chronic psychopathology. In B. A. van der Kolk, A. C. McFarlane, \& L. Weisaeth (Eds.), Traumatic stress: The effects of overwhelming experience on mind, body, and society (pp. 77-101). New York: Guilford Press.

Silvern, L., Waelde, L. C., Baughan, B. M., Karyl, J., \& Kaersvang, L. L. (2000). Two formats for eliciting retrospective reports of child sexual and physical abuse: Effects on apparent prevalence and relationships to adjustment. Child Maltreatment, 5(3), 236-250.

Smith, D., Letourneau, E. J., Saunders, B. E., Kilpatrick, D. G., Resnick, H. S., \& Best, C. L. (2000). Delay in disclosure of childhood rape: Results from a national survey. Child Abuse \& Neglect, 24, 273-287.

Springer, K. W., Sheridan, J., Kuo, D., \& Carnes, M. (2007). Long-term physical and mental health consequences of childhood physical abuse: Results from a large 
population-based sample of men and women. Child Abuse \& Neglect, 31(5), 517-530.

Taylor, G. J. (2000). Recent developments in alexithymia theory and research. Canadian Journal of Psychiatry, 45(2), 134-142.

Ullman, S. E. (2003). Social reactions to child sexual abuse disclosures: A critical review. Journal of Child Sexual Abuse, 12(1), 89-121.

van der Kolk, B. A., Weisaeth, L., \& van der Hart, O. (1996). History of trauma in psychiatry. In: B. A. van der Kolk, A. C. McFarlane, \& L. Weisaeth (Eds.), Traumatic stress: The effects of overwhelming experience on mind, body, and society (pp. 47-74). New York: Guilford Press.

Wekerle, C., Wolfe, D. A., Hawkins, D. L., Pittman, A., Glickman, A., \& Lovald, B. E. (2001). Childhood maltreatment, posttraumatic stress symptomatology, and adolescent dating violence: Considering the value of adolescent perceptions of abuse and a trauma mediational model. Development \& Psychopathology, 13(4), 847-871.

Zlotnick, C., Mattia, J. L., \& Zimmerman, M. (2001). The relationship between posttraumatic stress disorder, childhood trauma, and alexithymia in an outpatient sample. Journal of Traumatic Stress, 14(1), 177-187.

Zlotnick, C., Shea, M. T., Begin, A., Pearlstein, T., Simpson, E., \& Costello, E. (1996). The validation of the trauma symptom checklist-40 (TSC-40) in a sample of inpatients. Child Abuse E Neglect, 20(6), 503-510. 